\begin{abstract}
I SAID NO:

THE IMPACT OF VOICING NON-CONSENT ON WOMEN'S PERCEPTIONS OF AND RESPONSES TO RAPE
\end{abstract}

\author{
by Natalie K. Cook
}

The current study explored the impact of voicing non-consent, defined as telling the perpetrator "no" or "stop" before or during unwanted sex, in relation to experiences of rape. Aims of the study were to determine: (1) if voicing non-consent was related to qualitative differences in rape experiences (e.g., familiarity with the perpetrator, type of resistance used, or label assigned to experience), and (2) if voicing non-consent was related to differences in how women respond to rape (e.g., level of distress, beliefs about recovery, or attributions of blame). A subsample of 223 rape victims obtained from a sample of 1,293 college women completed anonymous questionnaires assessing past sexual victimization, characteristics of assault experiences, responses to the event, and symptoms of distress. Results indicated that voicing of non-consent was associated with increased likelihood of using physical resistance, greater endorsement of the rape label, and elevated PTS symptoms. Implications for intervention are discussed. 


\title{
I SAID NO: \\ THE IMPACT OF VOICING NON-CONSENT ON WOMEN'S PERCEPTIONS OF AND RESPONSES TO RAPE
}

\author{
A Thesis \\ Submitted to the \\ Graduate School \\ in partial fulfillment of \\ the requirements for the degree of \\ Master of Arts \\ Department of Psychology \\ by \\ Natalie K. Cook \\ Miami University \\ Oxford, Ohio \\ 2015
}

Chair

Terri L. Messman-Moore, Ph.D.

Reader Margaret O’Dougherty Wright, Ph.D.

Reader Elizabeth Kiel Luebbe, Ph.D. 


\section{Table of Contents}

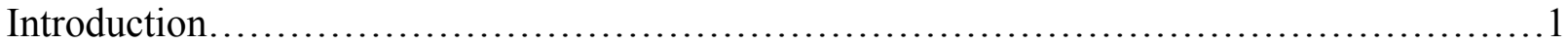

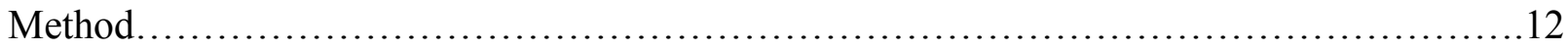

Results...................................................................... 16

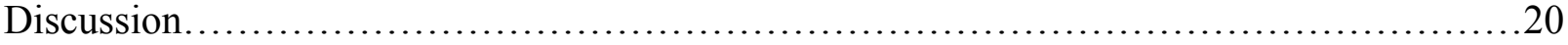

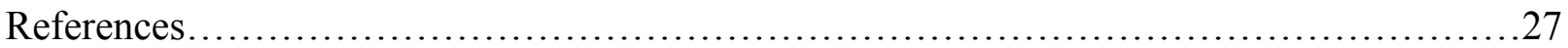

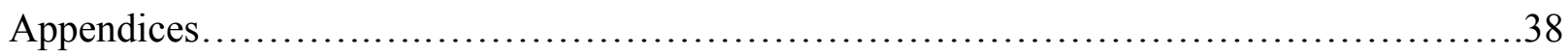




\section{List of Tables}

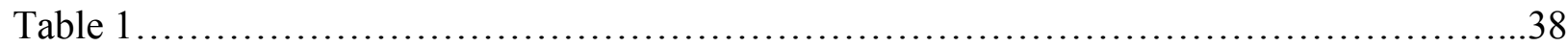

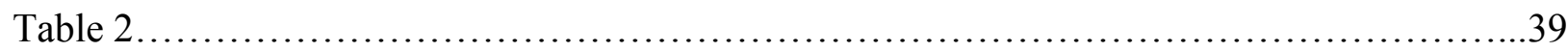

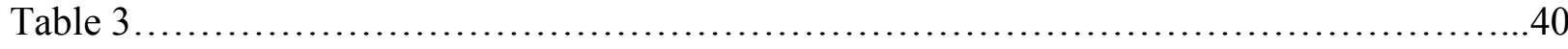




\section{List of Figures}

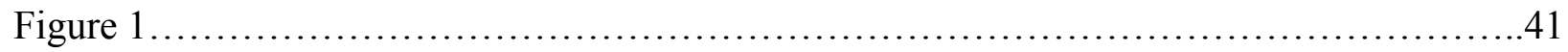


I Said No: The Impact of Voicing Non-consent on

Women's Perceptions of and Responses to Rape

Discussions of rape, sexual assault, and sexual consent are abundant in the media. Recently, media reports and public outrage have scrutinized institutions, from colleges and universities to the military and professional sports teams. The alleged rape cases at Vanderbilt, Notre Dame, Stubenville, Florida State, Maryville, and Duke are several recent high-profile examples where cases of reported rape were ignored or dismissed (Gray, 2014; Rabin, 2011; Rubenfeld, 2014). Professional football players, such as Darren Sharper and Ben Roethlisberger have been able to avoid six and two separate rape allegations respectively (Goldman, 2010; Rosenberg \& Evans, 2014). The victim-berating trial that occurred within the U.S. Naval Academy, the dismissal of convictions against an Air force fighter pilot and an Army Reserve sergeant, and the harassment received by service women who report incidents of rape and sexual assault, illustrate that even those who protect and serve our country are not immune from the problems rape and sexual assault (Henneberger \& Shin, 2013; Marshall, 2008). Despite certain claims that incidents of rape and sexual assault are declining (Fahrenthold, 2006; Leinwand, 2009), these issues appear to be just as pervasive as ever (Black, Basile, Breiding, Smith, Walters, Merrick, ... \& Stevens, 2010; CDC, 2010). Part of the dilemma is rooted in the vast underreporting of rape and the rarity of official criminal reports and arrests (Federal Bureau of Investigation, 1991; Heany, 2012; Lonsway \& Archambault, 2012; Kilpatrick, Resnick, Ruggiero, Conoscenti, \& McCauley, 2007; Koss, 1998; Tjaden \& Thoennes, 2000).

Researchers attempting to identify the prevalence of rape and to reduce underreporting have utilized behaviorally-specific screeners and questionnaires (Cook \& Koss, 2005; Koss, Abbey, Campbell, Cook, Norris, Testa, ... \& White, 2007; Koss, Gidycz, \& Wisniewski, 1987; Koss \& Oros, 1982; Peterson \& Muehlenhard, 2007), and have in fact provided compelling evidence to change the discourse regarding the prevalence of rape. The prevalence of rape and other forms of sexual victimization among women, once thought to be rare, are now acknowledged to be as high as $27 \%$ for rape, and 50\% for some degree of unwanted sexual activity (Black et al., 2010; CDC, 2010 Cook \& Koss, 2005; Gavey, 1991; Koss, 1998; Koss et al., 1987; Resnick, Kilpatrick, Dansky, Saunders, \& Best, 1993). This means that as many as 1 out of 4 women will experience a rape in her lifetime, while 1 out of 2 will experience some form of unwanted sexual activity. Rape and sexual assault are particularly common among 
college women; more than half of all college women have experienced some form of sexual victimization, with prevalence rates between 10-19\% for completed and attempted rape (Fisher, Cullen, \& Turner, 2000; Krebs, Lindquist, Warner, Fisher, \& Martin, 2009; Messman-Moore, Coates, Gaffey, \& Johnson, 2008). It has become recognized that women are far more likely to be raped by an acquaintance than a stranger (Black et al., 2010; Frazier \& Seales, 1997; Koss, 1992, 1998; Koss \& Cook, 1998; Koss \& Harvey, 1991; Muehlenhard \& Linton, 1987; Russell 1982, 1984; Weis \& Borges 1973), and that false reports of rape are extremely low (Kilpatrick, 2004; Lonsway, 2008, 2010; Muehlenhard, Sympson, Phelps, \& Highby, 1994; Parker \& Brown, 2000).

Rape is often assumed to involve a violent attack or the use of excessive physical force (Bondurant, 2001; Kahn, Andreoli, Mathie, \& Torgler, 1994; Layman, Gidycz, \& Lynn, 1996); however, this is not always the case. Rape experiences are categorized by the method of coercion involved: force or incapacitation (Brown, Testa, \& Messman-Moore, 2009). Rape resulting from force (i.e., forcible rape) occurs when a perpetrator uses or threatens to use physical force (or a weapon) to obtain sex, whereas rape resulting from incapacitation (i.e., substance-facilitated or incapacitated rape) occurs when the victim is too intoxicated to consent to sex (Brown et al., 2009). Research has shown that in the college population, substance facilitated rape occurs as often, if not more often, than rape resulting from force (Kilpatrick et al., 2007; Testa, Livingston, Vanzile-Tamsen, \& Frone, 2003).

\section{Psychological Impact of Sexual Assault and Rape}

Not all individuals respond to rape in the same manner, and a variety of characteristics known to impact the development of general distress and symptoms specific to Posttraumatic Stress Disorder (PTSD) have been documented. Risk factors for PTSD include experiencing injury during the rape, having a more violent assault, the involvement of multiple perpetrators, and confusion or disorientation during the assault (Acierno, Resnick, Kilpatrick, Saunders, \& Best, 1999; Ellis, Atkeson, \& Calhoun, 1981; Kilpatrick, Acierno, Resnick, Saunders, \& Best, 1997; Norris \& Feldman-Summers, 1981; Resick, Churchill \& Falsetti, 1990). An individual's history prior to rape also influences post-rape symptoms. Prior psychiatric treatment and previous history of anxiety, depression, alcohol abuse, or physical health problems predict further depression and poorer adjustment (Acierno et al., 1999; Calhoun, Atkeson, \& Resick, 1982; Frank, Turner, Stewart, Jacob, \& West, 1981; Koss, 1985; Resick, 1993). The biographic 
and demographic characteristics of women who have experienced rape ${ }^{1}$ have been examined. Being married, being employed, being older, having a lower socioeconomic status (SES), and being an ethnic minority contribute to higher psychological distress post-rape (Calhoun et al., 1982; McCahill, Meyer, \& Fischman, 1979; Resick, 1993; Ruch \& Chandler, 1983). Post-rape factors that increase PTSD symptomology include acknowledgment status (although results have been mixed and inconsistent), negative responses of others, self-blame, and overall lack of social support (Resick, 1993; Resick \& Schnicke, 1990).

The psychological consequences of different rape experiences may vary based upon the method of coercion. Research examining the emotional and psychological consequences of rape involving different methods of coercion found that substance-facilitated rape is associated with different patterns of distress than forcible rape. Women who experienced forcible rape reported the greatest number of symptoms consistent with PTSD, and expressed the highest degree of negative affect. Women who experienced substance-facilitated rape reported fewer symptoms consistent with PTSD (Abbey, BeShears, Clinton-Sherrod, \& McAuslan, 2004; Brown et al., 2009). Women also differed on the amount of trauma they perceived at the time of the event, with victims of forcible rape reporting more traumatic experiences than victims of substancefacilitated rape (Brown et al., 2009). Overall, research supports the idea that the severity of longterm consequences associated with substance-facilitated rape fall somewhere in between those associated with forcible rape and unwanted sex that occurs via verbal coercion (Abbey et al., 2004, Brown et al., 2009). Work in this field supports the idea that qualitatively different experiences of rape can result in different consequences.

However, some research suggests that these differences may be attributable largely to differences in how women interpret the meaning of their experience. Prior work has shown that qualitatively different experiences of rape are associated with both quantitative differences in levels of psychological distress (Acierno et al., 1999; Brown et al., 2009; Ellis et al., 1981; Kilpatrick et al., 1987; Norris \& Feldman-Summers, 1981; Resick et al., 1990), as well as different meanings or views regarding the unwanted sexual experience (Gavey, 1992,1999). A variety of event characteristics and cognitive factors may impact the meaning making process

\footnotetext{
${ }^{1}$ It should be acknowledged that not all women who have experienced an event consistent with definitions of rape will perceive themselves to have been raped, nor will all women perceive themselves as victims. However, for the purposes of brevity, women who have had such an experience will often be referred to as rape victims throughout the manuscript.
} 
and ultimately the way a woman comes to view her unwanted experience. One important and relatively understudied factor that may impact distress is the act of verbally expressing or 'voicing non-consent.' The current study postulates that the voicing of non-consent before or during unwanted sex is a significant factor that contributes to a qualitatively different experience of rape, impacts the resulting meaning making process, and translates into quantitative differences in symptomology post-rape.

\section{The Notion of Non-Consent}

A recent focus of both researchers and legal experts has been the definition of the consent standard in relation to legal definitions of rape. However, what researchers believe constitutes non-consent in the psychological literature is not always congruent with how consent is defined in the legal discourse. The English common law defined rape as carnal knowledge of a woman forcibly and against her will (Blackstone, 1765; MacKinnon, 2001). Currently, most states still define rape using the same three components: penetration, force, and lack of consent (Decker \& Baroni, 2012; Lyon, 2004; Remick, 1993). This definition can be problematic, allowing for ambiguity in regard to what constitutes consent. Both for perpetrators, and even within a court of law, verbal signals (including voicing non-consent) are often viewed as secondary to nonverbal signals for indicating consent. Among men, certain behaviors that women engage in (e.g., wearing revealing clothing, drinking or doing drugs, dancing suggestively, being on birth control, letting the man pay for or drive to a date, and meeting a man at his house) are considered signs of consent, and may actually be weighted more heavily than the actual voicing of nonconsent (i.e., saying "no") to determine if sex will occur (Gavey, 1999; Krause, DeRosa, \& Roth, 2002; Muehlenhard \& Linton, 1987; Pineau, 1989; Remick, 1993). Consider the following example from case law:

If a woman previously consented to any connection with a man- developing a friendship with a male colleague or superior at work, accepting a date, going to a bar or a party and talking with a man (i.e., making a stranger a non-stranger through conversation), agreeing to drive a man she has just met to his home, allowing a man she just met to drive her home, dating a man for an extended period of time, consenting to sexual relations with a man once or many times, cohabitating with a man, marrying a man- a presumption arises that she subsequently consented to sexual contact during the incident in question (Remick, 1993, p. 23).

Despite clear expressions of verbal non-consent on the part of the female victim, legal courts have acquitted defendants of sexual assault charges on the basis of the woman's promiscuity, 
good looks, bad looks, drinking habits, and dancing, among other behaviors (Remick, 1993). In other words, men often believe, and legal courts sometimes agree, that the woman has already "consented" with her prior behavior (Lonsway, 2010), so there is no need to take into account a voicing of non-consent later.

As the above examples illustrate, in many states verbal resistance or verbal non-consent (saying no before or during an act of unwanted sex) is not sufficient to prove the non-consent component of rape (Berliner, 1991; Remick, 1993). However, within the past ten years 17 states (led by Illinois) have redefined rape so that an individual may withdraw his or her consent at any time and so that the stereotypical use of force need not be present (Decker \& Baroni, 2012; Lyon, 2004). In September 2014, the state of California took this one step further by enacting a 'yes means yes' law, requiring affirmative consent for sexual activity. Lack of protest, lack of resistance, and silence are unable to be interpreted as signs of consent under this new law (Chumley, 2014). Despite groundbreaking progress in the evolution of rape and consent definitions, many individuals (men and women alike) still believe that once a woman has given verbal consent, subsequent verbal (or nonverbal) non-consent are seen as less important and can be rationalized away or dismissed (Power, 2012). Unfortunately, such verbal indications of nonconsent are even still frequently interpreted as consenting by the perpetrator (Berkowitz, 1992).

In fact, research indicates that one of men's most frequently used sexual coercive strategies is ignoring women's protests (Harned, 2013; Rapaport \& Burkhart, 1984), or “just doing it, even after the woman said no" (Muehlenhard \& Linton, 1987, p.193). Furthermore research reveals that a woman must say 'no' an average of three times before a man starts to believe she means it (Mills \& Granoff, 1992). Often underlying the perpetrator's actions is the belief that women frequently say "no" when they actually mean "yes" so as not to seem "easy" or "loose" (Kanin, 1967, 1969; Muehlenhard, 2011; Muehlenhard \& Felts, 1986; Muehlenhard \& Hollabaugh, 1988; Weis \& Borges, 1973). This is the idea of "token resistance," defined as saying no to sex but actually meaning yes. In Western society, research has shown that sexual scripts for men involve ignoring resistance (both verbal and physical) from women because they believe it is merely a "token resistance," and that ultimately ignoring these protests will lead to sex (Decker \& Baroni, 2012; Humphreys \& Herold, 2007; Muehlenhard \& Linton, 1987; Power 2012). Men who have a strong belief that women engage in token resistance do not perceive a verbal 'no' as a sufficient refusal (Osman, 2003). Women have been found to engage in token 
resistance to sex, and given society's gender roles when it comes to sex, token resistance may be an understandable behavior for some women (Muehlenhard \& Hollabaugh, 1988). However, the assumption that all women engage in token resistance is both inaccurate and dangerous (Muehlenhard \& Hollabaugh, 1988), as is the assumption that all voicing of non-consent is attributable to token resistance.

\section{Reasons Why Women May Not Voice Non-Consent}

Other recent research has examined why some women may choose not to engage in voicing non-consent. Reasons some women have reported for choosing not to voice their nonconsent include feeling uncomfortable, fearing it would increase the use of physical force, and fearing that continuation after voicing non-consent would make the experience seem more like rape (Gavey, 1999; Krause et al., 2002; Lebowitz \& Roth, 1994; Muehlenhard \& Linton, 1987; Power, 2012; Roth \& Lebowitz, 1988; Roth, Lebowitz, \& DeRosa, 1997). Some reports from women suggest that choosing to refrain from voicing non-consent or using other forms of resistance may actually act as a protective device:

Ann: Because there is always that fear that you could say no and it would carry on anyway, and, and being physically less, and then you'd be raped sort of thing, and then it would be terrible (Gavey, 1992, p.334). Ann: If I tried it, if I'd resisted, then he might rape me, you know (Gavey, 1992, p.339).

The example shows that some women believe that to view their unwanted experience as rape would have been worse than viewing it as something else (e.g., miscommunication). Viewing the experience as rape could increase the likelihood that the woman will perceive herself as more vulnerable, less in control, and as having less power. Similarly, previous research suggests that an important reason women give for not labeling their experience as rape is to preserve their view of self-agency (Phillips, 2000). The choice that Ann made, to not engage in verbal and nonverbal resistance, allowed her to not define her experience as rape, psychologically giving her an increased perception of control and possibly decreasing her distress (Gavey, 1999; Walker, 2007). The underlying message endorsed by at least some women is that it would be worse to resist or to tell the perpetrator 'no' and have him continue than to refrain from saying no at all. This suggests that cognitive factors, including the importance and meaning of the trauma to the individual, play a role in the development of later distress and disorder.

\section{Meaning Making Following Traumatic Events}

The voicing of non-consent is one of many factors that likely play a role in determining how women vary in understanding their unwanted sexual experiences, particularly rape, and how 
such understanding impacts their level of distress post-rape. Several theories posit that traumarelated distress results from the inability of the victim to incorporate the traumatic event into preexisting beliefs, or schemas, about the self, others, and the world (Horowitz, 1997; JanoffBulman, 1985; McCann, Sakheim, \& Abrahamson, 1988). These theories suggest that integrating the rape experience into one's current schematic beliefs is an important aspect of recovery. The schemas that tend to be in direct contradiction to these themes are those of personal invulnerability, along with beliefs that the self has worth, that the world is a meaningful and just place, and that people are generally good and can be trusted (Hollon \& Garber, 1988; JanoffBulman, 1985; Littleton, 2007; Littleton \& Grills-Taquechel, 2011; McCann \& Pearlman, 1990; Resick \& Schnicke, 1992; Roth et al., 1997). The shattering of these beliefs leads to anxiety, depression, negative self-image, self-blame, feelings of powerlessness, and a decreased ability to trust the self and others (Janoff-Bulman, 1985; McCann et al., 1988).

It has been theorized that rape victims use different types of strategies in an attempt to reconcile their rape experience with their prior beliefs. These strategies are sometimes characterized as indicative of assimilation, accommodation, and overaccommodation (Littleton, 2007; Littleton \& Grills-Taquechel, 2011; Resick \& Schnicke, 1992). Assimilation involves altering one's perception of the event to fit with pre-existing schemas and typically does not include conceptualizing the experience as traumatic or as "rape." Instead, the unwanted experience is attributed to a miscommunication, or women blame themselves for being in the wrong place at the wrong time. Self-blame is often a marker of assimilation (Resick \& Schnicke, 1992). Accommodation involves altering pre-existing schemas to fit the trauma, and typically includes acknowledging the assault took place and adapting current world beliefs to incorporate the experience. Accommodation has been theorized to be the healthiest way to integrate a rape experience into current schematic beliefs, although it does not come without some level of distress (Resick \& Schnicke, 1992). Overaccommodation involves engaging in maladaptive schema change. Assumptions that the world is a dangerous place, that others are not to be trusted, that all men are dangerous, and that the self is unworthy may become overgeneralized.

These ideas have been generally supported and have been developed into an effective therapy, known as Cognitive Processing Therapy (CPT) (Resick \& Schnicke, 1992). CPT has been shown to reduce symptoms of PTSD, depression, and self-blame (Resick \& Schnicke, 1992; Resick, Williams, Suvak, Monson, \& Gradus, 2011; Wachen, Jimenez, Smith, \& Resick, 
2014). However, empirical examination of assimilation, accommodation, and overaccommodation has been sparse. One study to date has attempted to examine these constructs (Littleton \& Grills-Taquechel, 2011), but falls short of adequately comparing women who have had similar experiences (i.e., rape). This study found that women who engaged in overaccommodation had the highest levels of PTSD, depression, and negative trauma-related schemas (Littleton \& Grills-Taquechel, 2011). However, contrary to theory, the study did not find elevated levels of distress among women who engaged in assimilation compared to women who engaged in accommodation (Littleton \& Grills-Taquechel, 2011). This may have been due to women engaging in assimilation being victims of sexual assault, unwanted sexual contact, or verbal coercion, as opposed to rape. Overall however, theory suggests that how a woman attributes meaning to her rape and how she processes this new information with her pre-existing schemas will likely impact her risk for the future development of PTSD, depression, and other negative mental health outcomes (Resick \& Schnicke, 1992).

\section{Rape Scripts, Labeling, and Non-Consent}

Voicing non-consent (i.e., saying "no" or "stop" to the perpetrator) is often assumed to occur during rape, and is therefore a part of a "rape script". A rape script refers to a stereotyped experience of rape, and usually includes elements such as being attacked by a stranger, physical violence and pain, and resistance from the victim (Kahn \& Mathie, 2000). Once such a script is activated, a woman is more likely to view her experience of unwanted sex as rape, which may impact the meaning making process and her resulting distress.

For at least some women, the activation of the rape script may make the subsequent process of integrating the rape experience with existing schemas more difficult than if the woman views her experience as something other than a rape. Research and clinical interviews have suggested that some women believe not identifying their experience as rape is protective or helpful in some way (Gavey, 1990, 1992, 1999; Roth \& Lebowitz, 1988). One tactic women may use to avoid activating a rape script is choosing not to voice their non-consent to the perpetrator. It is likely that the act of voicing non-consent before or during a completed rape increases the accessibility of the rape script and increases the likelihood that the victim will experience a greater number or a greater level of rape themes discordant with pre-rape schemas (e.g., helplessness or powerlessness, loss, rage or anger, fear, self-blame or self-mistrust) (Horowitz, 1997; Janoff-Bulman, 1985; Krause et al., 2002; McCann \& Pearlman, 1990; Roth \& Newman, 
1993). The more pieces of conflicting information the victim experiences and must process, the more difficult or prolonged recovery may be.

Another tactic women often use to avoid activating a rape script is using a label other than rape to describe their experience. Research consistently shows that only $12 \%-57 \%$ of women who endorse behaviorally-specific descriptions of rape actually label their experience as rape (Frazier \& Seales, 1997; Harned, 2004; Kahn, Jackson, Kully, Badger, \& Halvorsen, 2003; Kahn et al., 1994; Koss, 1985; Koss et al., 1987; Layman et al., 1996). Some studies show that labeling an unwanted sexual experience as rape may have negative consequences for the victim, including increased symptoms of distress and PTSD, or increased feelings of victimization (Kahn et al., 2003; Kahn \& Mathie, 2000; Layman et al., 1996). Some studies suggest that the label itself doesn't matter, and that distress levels are not correlated with whether or not a woman labels her experience as rape. Rather, distress is correlated with the unwanted sexual experience in general (Harned, 2004). Other studies suggest that labelers are less distressed than nonlabelers and show more closure and better adjustment (Botta \& Pingree, 1997; Gidycz \& Koss, 1991). Although studies have found mixed results regarding the consequences of labeling, research agrees that voicing non-consent is a key factor in the labeling process and activation of a rape script (Harned, 2013; Peterson \& Muehlenhard, 2007).

Women who are victims of rape who voiced their non-consent could be more likely to label their experience as rape (Harned, 2013; Peterson \& Muehlenhard, 2007). This may be associated with greater endorsement of negative traumatic themes. Helplessness or powerlessness may be heightened among rape victims who voice non-consent. It is now widely recognized that the goal of rape is more about disempowering the victim than about obtaining sex; rape is sometimes thought of as the ultimate disempowerment of women (Browne \& Finkelhor, 1986; McCann et al., 1988; Thompson, 2000). Women who voice non-consent may experience an even greater degree of disempowerment than women who do not voice nonconsent. Voicing non-consent but having it fail to stop the unwanted sexual activity is a direct message of the lack of control and power a woman has (Gavey, 1999; Kahn et al., 2003; Phillips, 2000).

Negative beliefs regarding helplessness, powerlessness, and loss of control may be exceptionally difficult to integrate into the pre-rape schemas women have about their invulnerability or efficaciousness. As a result of these difficulties, women who voice non- 
consent might experience increased levels of psychological distress, elevated above and beyond that of rape victims who did not engage in voicing non-consent, translating into a longer time to recovery. In summary, we might expect victims who voice non-consent to have more psychological distress and longer periods of recovery than those victims who do not voice nonconsent because the perpetrator's failure to stop the unwanted activity increases the woman's sense of powerlessness and helplessness.

\section{Summary}

Increased distress post-rape has been linked to an inability to incorporate a traumatic event into pre-rape schematic beliefs (Horowitz, 1997; Janoff-Bulman, 1985; McCann et al., 1988). Integrating an unwanted sexual experience into pre-rape beliefs is thought to be an important aspect of recovery (Horowitz, 1997). Research has already identified a number of factors that impact how a woman derives meaning from an unwanted sexual experience, and how some of these factors translate into different levels of distress post-rape (Acierno et al., 1999; Brown et al., 2009; Calhoun et al., 1982; Ellis et al., 1981; Kilpatrick et al., 1987; Norris \& Feldman-Summers, 1981; McCahill et al., 1979; Resick, 1993; Resick \& Schnicke, 1990; Resick et al., 1990; Ruch \& Chandler, 1983). An additional factor that contributes to a qualitatively different experience of rape that has not yet been examined quantitatively is the voicing of nonconsent before or during rape. Reasons why women may or may not choose to voice non-consent have been examined in qualitative interviews (Gavey, 1992, 1999), but to date no research exists that examines descriptive patterns surrounding the voicing of non-consent, or how the voicing of non-consent translates into quantitative differences in symptomology post-rape. Despite the popularity of discussions of consent in the media, the actual proportion of women who engage in voicing non-consent is surprisingly unknown. Furthermore, women who voice non-consent may show a different pattern of psychological distress, PTSD symptomology, depressive symptoms, and thoughts about recovery than women who do not voice non-consent given how the act of voicing non-consent impacts the meaning making process. Finally, given that prior childhood sexual abuse has been shown to impact the likelihood of adolescent and adult sexual victimization (Messman-Moore \& Long, 2003), and that childhood sexual abuse may contribute to schemas of disempowerment (Finkelhor \& Browne, 1985), the potential impact of childhood sexual abuse on the likelihood of voicing non-consent will be examined. Contributing knowledge about how the voicing of non-consent impacts distress post-rape may inform intervention with 
victims, and may also provide evidence to advocate for a 'yes means yes' standard in the legal discourse of rape.

\section{Hypotheses}

The present study examines whether voicing non-consent by telling the perpetrator to stop the unwanted activity is a factor that impacts the overall experience of the rape and the subsequent meaning making process. The voicing of non-consent is hypothesized to be related to specific characteristics of the rape itself, including the degree of force or type of coercion used by the perpetrator, the degree and type of resistance used by the victim, and the relationship between the victim and the perpetrator. Furthermore, voicing non-consent is hypothesized to impact women's attributions of responsibility for the rape, and their responses to rape, including their degree of psychological distress and beliefs about recovery.

Primary Aim - Assault Characteristics. The primary aim of the proposed study is to determine whether the voicing of non-consent is related to qualitative differences in rape experiences. The likelihood of voicing non-consent may vary depending on the relationship between the victim and the perpetrator, with willingness to voice non-consent to a stranger or acquaintance being more likely than to an intimate partner. Additionally, prior research indicates voicing non-consent increases the likelihood of a woman perceiving (e.g., labeling) her experience as rape (Harned, 2013), and that labeling an unwanted experience as rape may also be related to the tendency to use more physical resistance. These possibilities will be explored. The following hypotheses will test the primary aim:

Among women reporting rape:

1. Voiced non-consent will be more likely if there is less familiarity or intimacy with the perpetrator (i.e., voiced non-consent more likely for assaults by a stranger versus an acquaintance, but more likely for an acquaintance versus an intimate partner).

2. Women who voice non-consent will be more likely to engage in physical methods of resistance.

3. Women who voice non-consent will have greater endorsement of a rape label as a description of their experience.

Secondary Aim-Responses to Rape. A secondary aim is to determine whether the voicing of non-consent is related to differences in psychological distress and recovery patterns after a rape. Voicing non-consent is hypothesized to be a key factor impacting how a woman 
makes meaning out of her experience and describes what happened to her. As a result, the voicing of non-consent might impact the meaning making process and the resulting level of psychological distress and beliefs about recovery. It is predicted that women who voice nonconsent will show increased levels of psychological distress (both PTSD-specific and more general symptoms), along with increased levels of negative beliefs surrounding their ability to recover and the time they believe it will take to do so. This hypothesis is based upon prior work suggesting that the perception of an unwanted sexual experience as rape proves the most difficult to integrate with existing schemas about the self, the world, and others (Kahn et al., 2003; Kahn \& Mathie, 2000; Layman et al., 1996), and on work suggesting that women who voice nonconsent and go on to be raped show the highest levels of disempowerment (Gavey, 1999; Kahn et al., 2003; Phillips, 2000). The following hypotheses will test the secondary aim: Among rape victims:

4. Voicing non-consent will be related to higher levels of Posttraumatic stress symptoms (PTSS).

5. Voicing non-consent will be related to less positive beliefs about recovery.

6. Voicing non-consent will be related to increased attribution of blame on the perpetrator and to decreased blame on the self.

Tertiary Aim - Voicing Non-consent and Other Unwanted Sexual Experiences. A third aim is to explore the link between non-consent and unwanted sexual experiences that fall short of meeting the research criteria for rape (i.e., sexual assault). Prevalence rates of voicing nonconsent during experiences of sexual assault will be explored, along with possible differences in distress post-assault. These analyses will be exploratory in nature; no specific hypotheses are proposed due to a lack of existing literature to support directional hypotheses.

\section{Method}

\section{Participants}

Participants were 223 college women who experienced rape since age 14, selected from an original sample of 1,293 college women drawn from a medium-sized Midwestern University. Participants' ages ranged from 17 to $33(\mathrm{M}=18.82, \mathrm{SD}=1.62)$, with most participants being White (91.5\%), unmarried, and from middle- to upper-SES (53.9\% reporting an income of at least $\$ 100,000)$.

\section{Procedure}


All procedures were approved by the Committee on the Use of Human Subjects in Research (CUHSR) at Miami University. Women were recruited through electronic experimental sign up boards and participated in exchange for course credit for Introductory to Psychology courses. Participants gave written informed consent after being given information about their rights as a research participant and the major objectives of the study. Participants were then given an envelope with a set of questionnaires marked with an ID number, making responses anonymous. Participants were told that they could refuse to answer any given question or withdraw from the study at any time without penalty. Women completed the surveys in small groups at their own pace, and upon completion were provided written and verbal debriefing information including contact information for the researchers and counseling resources.

\section{Measures}

Demographics. Demographic information, including age, education, race/ethnicity, and annual income, was collected using the Life Experiences Survey (LES), a self-report instrument.

Adult \& Adolescent Sexual Victimization. Sexual victimization in adolescence and early adulthood was assessed with a modified version of the Sexual Experiences Survey (MSES; Koss et al., 1987; Messman-Moore, Walsh \& DiLillo, 2010). The survey contains 17 yes or no questions pertaining to specific types of unwanted sexual activity occurring after the age of 14 . These experiences include sexual contact (kissing, fondling), oral sex, vaginal or anal intercourse, and penetration by objects (including fingers or other objects). Items are presented in order of escalating severity. Participants who indicate experiences of sexual victimization on the MSES were asked to complete follow-up questions regarding the characteristics of the most distressing unwanted sexual experience.

Characteristics of Assault. In the follow up questions, participants were asked to indicate how long ago the event occurred, their age at the time, the perpetrator's age at the time, and the nature of their relationship. Participants also indicated what substance(s) were used and rated how intoxicated both she and the perpetrator were on a scale from 1 (not at all) to 5 (very). Perpetrator tactics assessed ranged from verbal pressure, to purposefully intoxicating the victim, to physical force; these items were adapted from previous research (Abbey et al., 2004). Victim resistance was assessed based on the 15 different protective actions set forth in National Crime Victimization Survey (NCVS) data, including physical resistance, forceful verbal resistance, non-forceful verbal resistance, and other types of protective actions, and have been used in prior 
research to examine the effectiveness of resistance strategies (Clay-Warner, 2002).

Voicing Non-Consent. The voicing of non-consent was one specific type of resistance strategy, and was embedded in the list of possible actions a woman could endorse. Women were considered to have voiced non-consent if they endorsed that they used verbal protesting (telling the perpetrator "no," "stop it," etc.). Additionally, women who endorsed the item "The other person just continued the unwanted sexual activity, without force, after you had said no," embedded in the list of possible tactics used by the perpetrator, were considered to have voiced non-consent.

Labeling. In addition to specific characteristics about the event, participants were instructed to reflect on (1) how they labeled the experience, (2) their attributions of responsibility, and (3) their beliefs about recovery. Labeling of sexual victimization experiences was assessed by having participants indicate to what extent they considered what happened to be rape, sexual assault, and non-consensual on a scale from 1 (not at all) to 7 (completely) to describe the extent to which they agreed with each label.

Attributions \& Recovery. Attributions of responsibility and beliefs about recovery were assessed using the Rape Attributions Questionnaire (RAQ; Frazier, 2003). The RAQ measures attributions for the cause of an unwanted sexual experience, including behavioral self-blame and perpetrator blame. Five items measure each construct, and participants answer items on a scale from 1 (never) to 5 (very often). Sample items include "I didn't do enough to protect myself" (self-blame) and "the man wanted to feel power over someone" (perpetrator blame). Both the self-blame $(\alpha=.89)$ and perpetrator blame $(\alpha=.80)$ subscales appeared to have good internal consistency. The RAQ also assesses present beliefs about recovery and control. Participants answered items on a scale from 1 (strongly disagree) to 5 (strongly agree). Sample items include "I feel like the recovery process is in my control" and "I don't feel there is much I can do to help myself feel better" (reverse scored). The internal consistency for the recovery subscale was somewhat questionable ( $\alpha=.66$ ), suggesting that examining individual items of the subscale might yield more valid interpretations. Unfortunately, due to an administrative error, the RAQ was only administered to 103 of the 223 women in the final sample.

Childhood Sexual Abuse. The data provided by the total sample of 1293 women was collected in two waves of data collection. Within these two sub-samples, two different instruments were used to assess childhood sexual abuse. In one wave of the collection $(n=747)$ 
participants were asked to complete the Computer Assisted Maltreatment Inventory (CAMI; DiLillo, Fortier, Hayes, Trask, Perry, Messman-Moore, ... \& Nash, 2006). The CAMI is a computer-based, self-report questionnaire designed to measure experiences of childhood maltreatment, including sexual abuse. For the purposes of the current study, participants were coded into groups based on their experience of child sexual abuse only. Experiencing sexual abuse was defined as reporting, before age 14, actual or attempted sexual contact (touching or kissing) or intercourse (oral, anal, vaginal) with either a family member or a person who was five or more years older. Voluntary sex play with similar aged peers or sexual activity with dating partners was not included. In the other wave of data collection $(n=546)$, the Childhood Trauma Questionnaire (CTQ; Bernstein et al., 2003) was used to assess childhood sexual abuse. The CTQ measures five types of child maltreatment (i.e., physical, sexual, and emotional abuse; physical and emotional neglect). Each abuse subscale is comprised of five items rated on a fivepoint scale, ranging from 1 (never true) to 5 (very often true) in response to the stem "When I was growing up ...”. The CTQ generates dichotomous victim classification scores ranging from 0 (abuse not present) to 3 (severe). After classification scores were given, participants' CSA status was recoded to form dichotomous (present/absent) classifications. Participants who acknowledged experiences consistent with mild, moderate, or severe childhood sexual abuse (scores of 1-3) were determined to have experienced childhood sexual abuse, and CSA was coded as present. For participants who did not report experiences of childhood sexual abuse (score of 0), CSA was coded as absent.

An overall indicator of CSA was created, based solely on the presence or absence of childhood sexual abuse in each sub-sample. A participant was said to have experienced CSA if they answered affirmatively to questions pertaining to CSA on either the CAMI or the CTQ. Prior research has shown a significant overlap between the CAMI and the CTQ when both measures were administered to the same respondents (DiLillo et al., 2006). Furthermore, given rates of childhood sexual abuse were nearly identical for each measure/sample, with the prevalence rate being $6.9 \%$ as measured by the CAMI and $6.5 \%$ as measured by the CTQ. Given the high overlap between the measures and the similar prevalence rates, using two separate measures of CSA to obtain an overall indicator of the absence or presence of CSA seems acceptable.

Psychological Distress. The Traumatic Symptom Inventory (TSI; Briere, 1996) a 100- 
item, self-report measure was administered to assess how often each symptom was experienced by participants over the past six months on a 4-point scale ranging from (1) never to (4) often. For the purposes of this study, only the subscales of anxious arousal (AA), intrusive experiences (IE), defensive avoidance (DA), and dissociation (DIS) were examined. These specific subscales were chosen based on their representation of the presence of PTSD-like symptoms. The TSI is commonly used to measure traumatic sequelae and has been found to have sound psychometric properties (Briere, 1995, 1996; Norris \& Hamblen, 2004). Internal consistency values in the sample were sound for all subscales (AA $\alpha=.82$, IE $\alpha=.89$, DA $\alpha=.90$ and DIS $\alpha=.84$ ).

\section{Results}

\section{Data Analysis Plan}

Analyses were preformed using SPSS21 statistical software to compare women who voiced non-consent to those who did not. Additionally, potential confounding variables such as time since assault and experience of physical injury were examined, and controlled for if significant differences were found between the two groups of women. For descriptive purposes, and to better understand why some women may not voice non-consent, level of intoxication and prior experience of CSA were also examined in relation to the presence or absence of voiced non-consent. The significance of these descriptive findings is reported and discussed below.

\section{Descriptive Statistics}

Overall, 21.0\% $(n=272)$ of the entire sample $(\mathrm{N}=1293)$ reported experiences that met the research definition of rape, defined as having had unwanted intercourse (oral, anal, or vaginal) due to a) physical force or threat of physical force by the perpetrator, or b) the participant being unable to give consent or resist as a result of her alcohol or drug use, since the age of 14 . However, seven of these women provided no additional data about their experience or levels of distress and were not included in subsequent analyses. Further, of the remaining 265 women, those who reported being unconscious (endorsing a 5 on a scale where $1=$ not at all and $5=$ very for the statement "I did not do anything because I was not conscious", n=41) were not included in subsequent analyses. Women who reported being unconscious were excluded due to their inability to have voiced non-consent. Additionally, women who reported experiences of childhood sexual abuse on the MSES ( $n=2)$ were also not included in subsequent analyses because they did not report an adolescent or adult sexual experience on the MSES. Women were not excluded if they reported childhood sexual abuse on one of the two CSA measures (CAMI 
and CTQ). This left a final sample of 223 women who had experienced completed rape (see Figure 1 for a complete breakdown of how final participants were selected).

Participants who endorsed attempted but not completed rape were also excluded from the analyses. The decision to exclude women who have experienced only attempted rape comes from previous literature suggesting that the way women experience and make meaning of attempted rape may differ greatly from how they do so for completed rape (Gavey, 1999).

Method of Coercion. For the remaining 223 women reporting a rape experience, diverse methods of coercion were reported, with $80.3 \%$ endorsing voluntary intoxication, $9.5 \%$ endorsing receiving alcohol or drugs without their knowledge, 10.3\% endorsing perpetrator threats, $29.3 \%$ endorsing use of force, and $76.1 \%$ endorsing that the perpetrator just continued after the woman said no. Interestingly, all of the women who endorsed receiving alcohol or drugs without their knowledge also endorsed voluntary intoxication. Additionally, almost all of the women (97.1\%) who endorsed threats also endorsed physical force. Only one woman endorsed threats and not force as coercion methods. This suggests that threats typically occur as a precursor to the use of force and rarely occur in isolation.

Voiced Non-consent. A majority (85.65\%) of the women who were raped reported voicing non-consent $(\mathrm{n}=191)$, whereas $14.35 \%(\mathrm{n}=32)$ did not voice non-consent. Experiencing prior CSA was not related to the likelihood of a participant voicing non-consent in a subsequent rape experience; $94.7 \%$ of CSA victims voiced non-consent and $85.4 \%$ of non-CSA victims voiced non-consent $\left(X^{2}(1, \mathrm{~N}=218)=1.27, p=.26\right)$. Consistent with the revictimization literature (Messman \& Long, 1996; Messman-Moore \& Long, 2003), the percentage of women who had experienced prior CSA was elevated in the sample of rape victims (8.7\% reporting CSA) compared to the overall sample (6.8\% reporting CSA). However, the total number of rape experiences reported on the MSES was not related to the likelihood of voicing non-consent $(r=$ $.06, p=.41)$.

Time since assault was transformed into a categorical variable, as recent (occurring within the past three months) or not recent (occurring longer than three months ago). The three month mark was identified as the cut point based on prior PTSD literature indicating that when PTS symptoms persist past the first three months, they tend to become chronic and less likely to remit naturally (Foa, Rothbaum, Riggs, \& Murdock, 1991; Rothbaum, Foa, Riggs, Murdock, \& Walsh, 1992). A majority of the women reported rapes that occurred longer than three months 
ago $(78.3 \%, \mathrm{n}=173)$, while fewer women reported rapes that occurred within the past three months $(21.7 \%, \mathrm{n}=48)$. It appeared that overall there were marginal differences between groups for time since assault $\left(X^{2}(1, \mathrm{~N}=220)=3.95, p=.05\right)$. Given this finding, later analyses examining psychological distress will include time since assault as a covariate. There were no significant differences between women who voiced non-consent and women who did not voice non-consent on the likelihood of physical injury, $\left(X^{2}(1, \mathrm{~N}=202)=2.65, p=.10\right.$, therefore physical injury was not included as a covariate in subsequent analyses. In addition, there were no significant differences in rates of voiced non-consent based upon method of coercion: $100 \%$ of women who were threatened voiced non-consent, $97.1 \%$ of women who experienced physical force voiced non-consent, and $84.0 \%$ of women who became intoxicated voiced non-consent. There was a significant difference between voiced non-consent groups on self-reported levels of intoxication, with women who did not voice non-consent $(M=4.23, S D=.86)$ reporting higher levels of intoxication than women who did voice non-consent $(M=3.26, S D=1.54), F(1,219)$ $=12.38, p=.001$.

\section{Voiced Non-consent \& Perpetrator Identity}

To examine the impact of perpetrator identity and intimacy on voiced non-consent, two separate Chi Square analyses were conducted. In the first chi-square, perpetrator identity was coded into six categories in order of ascending intimacy: 1) stranger, 2) non-intimates (comprised of classmates, coworkers, bosses, and acquaintances), 3) friends, 4) new casual intimates (comprised of new hook-up partners, and casual dates $<5$ ), 5) known casual intimates (comprised of known hook-up partners, and casual dates 5+), and 6) current or ex-partners (comprised of spouse, ex-spouse, current steady dating partner, and ex-steady dating partner). In this $6 \times 2$ chi-square the relative frequencies of those who voiced non-consent and did not voice non-consent were examined across different levels of perpetrator familiarity. However, no significant differences were found, $X^{2}(6, \mathrm{~N}=217)=9.55, p=.15$. With a null result being possible due to too few participants in each cell, a second chi-square analysis was conducted where perpetrator identity was coded into either 1) intimate (comprised of new casual intimates, known casual intimates, and current and ex-partners) or 2) non-intimate (comprised of strangers, non-intimates, and friends). The second chi-square also revealed that the level of intimacy between the victim and perpetrator was not related to the voicing of non-consent, $X^{2}(2, \mathrm{~N}=217)$ $=1.45, p=.48$. 


\section{Voiced Non-consent \& Physical Resistance}

Participants were presented with seven possible physical resistance strategies and were asked to indicate if they engaged in each of the resistance strategies. Physical resistance was said to have occurred if the woman endorsed any one or more act of physical resistance as presented in the sexual victimization questionnaire (shielding body, physically pushing or shoving, biting or scratching, hitting, kicking, kneeing, or throwing objects). The relationship between voiced non-consent and the use of physical resistance was examined using a 2 × 2 chi-square. The absence of voiced non-consent was related to physical resistance, $X^{2}(1, \mathrm{~N}=213)=32.82, p$ $<.001, \phi=.39$. Of the women who did not voice non-consent, $79.3 \%$ did not resist physically, while $20.7 \%$ did resist physically. These percentages differ significantly from the expected values.

\section{Voiced Non-consent \& Labeling}

A MANOVA was conducted to examine whether women who voiced non-consent differenced from those who did not in the use of three possible labels of participants' experiences: 1) rape, 2) sexual assault, and 3) consensual. Women who voiced non-consent endorsed higher labels of rape and sexual assault, along with indicating the experience was less consensual than women who did not voice non-consent (See Table 1). Despite significant differences between voiced non-consent groups, labels of rape and sexual assault remained fairly low for both groups (See Table 3).

\section{Voiced Non-consent \& Posttraumatic Stress Symptoms}

Another MANOVA was conducted to examine whether women who voiced non-consent differed from those who did not on posttraumatic stress symptoms. Time since assault was included as a covariate in the analysis. The multivariate test revealed significant differences between women who did voice non-consent and women who did not voice non-consent on measures of posttraumatic stress symptoms, with women who voiced non-consent reporting higher symptom levels (Wilks' $\Lambda=.954 ; F(4,212)=2.55, p=.04$ ). Significant differences occurred between groups on the subscales measuring intrusive experiences (IE), defensive avoidance (DA), and dissociation (DIS). No significant differences were found on the subscale measuring anxious arousal (AA) (See Table 1).

\section{Voiced Non-consent \& Recovery and Blame}


A MANOVA was also conducted to examine the RAQ recovery and blame scales controlling for time since assault. The omnibus F test including all three subscales was not significant (Wilks' $\Lambda=.940, F(3,98)=2.10, p=.11)$. However, due to the questionable alpha of the recovery subscale, analyses were conducted again examining the significance of the selfblame and perpetrator blame subscales separately, and the significance of individual items from the recovery scale. Alone, the perpetrator blame subscale showed significant differences between voiced non-consent groups with perpetrator blame being higher among women who voiced nonconsent, $F(1,97)=4.78, p=.03$. The self-blame subscale showed only marginal differences between groups, in the direction of women who voiced non-consent reporting higher level of self-blame, $F(1,97)=3.81, p=.05$. A MANOVA conducted on the individual items of the recovery subscale did not yield a significant omnibus $F$ test, Wilks' $\Lambda=.92, F(5,92)=1.52, p=$ .19. (See Table 1 for details).

\section{Tertiary Aim}

Overall, 54 women endorsed having an experience that met the research definition of sexual assault. However, of these 54 women, only 11 uniquely endorsed experiencing a sexual assault, while the remaining 43 women who reported an experience of sexual assault also met criteria for experiencing a rape. Of the remaining 11 women, one reported being unconscious (endorsing a 5 on a scale where $1=$ not at all and 5= very for the statement "I did not do anything because I was not conscious"), leaving a sample of only 10 women for analyses on sexual assault. Due to the small sample size, no additional analyses could be conducted to examine the impact of voicing non-consent for women who had experiences of sexual assault.

\section{Discussion}

The vast majority (approximately 85\%) of women who experienced rape did voice nonconsent during the unwanted sexual activity. Surprisingly, results showed that only a relatively low number (14.35\%) did not engage in voicing non-consent. This was true across all methods of coercion, with women reporting alcohol-related rape being just as likely to voice non-consent as those reporting rape that occurred due to force or threats. Moreover, the experience of prior sexual violence (either CSA or adult victimization) was unrelated to the likelihood of voicing non-consent and was not influenced by prior victimization. However, higher levels of intoxication during the assault were associated with a lower likelihood of voiced non-consent. The finding that the large majority of rape victims actually voice non-consent has not yet been 
discussed in the literature. Previous research has found that some women are reluctant to engage in voicing non-consent; these women state that if the perpetrator continued after she said no, she would feel worse than if she had actually abstained from saying no (Gavey, 1992, 1999, 2005). Given that prior research has not yet explored the existence of quantitative differences in outcomes between women who do and do not voice non-consent during rape, the present study adds to the literature by examining descriptive patterns associated with voicing non-consent in a large sample of female college rape victims. Consistent with prior literature, we found that the voicing non-consent was associated with higher levels of distress (Gavey, 1999, 2005). Results of the current study indicate that women who voice non-consent before or during rape experience greater symptoms associated with PTSD, including higher levels of intrusive experiences (i.e. reexperiencing the rape or unwanted thoughts of the rape), dissociative symptoms (i.e. depersonalization or derealization), and symptoms of avoidance (i.e. avoiding thinking or talking about the rape, avoiding people or places that remind her of the rape, emotional numbing) compared to women who did not voice non-consent before or during rape.

Researchers examining the role consent plays in rape and sexual assault often cite the miscommunication hypothesis as a viable explanation or contributing factor to rape and sexual assault (Beres, 2010; Byers, 1996; Gray, 1992). The miscommunication hypothesis is the assumption that many instances of acquaintance rape are a result of miscommunication and misreading of signals between men and women (Gray, 1992). This hypothesis asserts that men often misunderstand women's sexual refusals, interpreting them as modesty or token resistance (Byers, 1996; Johnson \& Jackson, 1988; Motley, 2008). As a result, researchers and intervention programs have spent a great deal of time focusing on how women can make clearer refusals (Schewe, 2002; Weitz, 2002). However, a small but growing number of studies have begun to illustrate the inaccuracy of the miscommunication hypothesis. These studies have found evidence that men fully understand women's repertoire of sexual refusals, and understand that continued sexual activity these refusals is unwanted (Abbey \& Jacques-Tiura, 2011; Beres, Senn, \& McCaw, 2014). Findings from the current study are another piece of growing evidence against the miscommunication hypothesis. Women are clearly communicating to men their lack of desire for sexual activity. A whopping $85 \%$ of women who were raped gave the single clearest indicator of lack of consent, a verbal 'no' or 'stop'. The findings from the current study also indicate that women who voice non-consent (verbal resistance) are also more likely to use 
physical methods of resistance. Coupled together, findings that women use both overt verbal and physical resistance, and that the substantial majority of women voice non-consent, add to a growing body of evidence that the miscommunication hypothesis is inaccurate, and that any 'misperception' is more likely deliberate disregard exhibited by the perpetrator.

Despite the fact that over $85 \%$ of women engaged in voicing non-consent, many did not endorse a high level of certainty that their experience was a rape or a sexual assault (See Table 3). This suggests that even though women are expressing their non-consent to the perpetrator and experiencing coercion via force or substance use, they are not labeling their experience a rape or labeling themselves as a victim. This finding is consistent with prior literature indicating that among rape victims, the tendency to label an experience as rape is low (Frazier \& Seales, 1997; Harned, 2004; Kahn et al., 2003; Koss, 1985; Koss et al., 1987; Layman et al., 1996). It is important to note the consistent findings from the current study to earlier research, as we used a different approach to assessing labeling. Prior research has assessed labeling by giving participants categorical, typically dichotomous, choices for which to answer a question about labeling. Examples include "Have you ever been raped by a man?", or "Do you consider what happened to be rape?” (Botta \& Pingree, 1997; Frazier \& Seales, 1997; Harned, 2004; Kahn et al., 2003; Kahn \& Mathie, 2000; Koss 1985; Koss, 1992; Layman et al., 1996). However, the current study assessed labeling using a Likert-type scale, which was chosen to allow participants to express ambiguity regarding labels, which may not have emerged in earlier studies using only forced choice responses. The Likert-type approach to labeling did indicate that ambiguity in labeling exists for rape victims. Findings indicated a high percentage of women voice nonconsent and also label the experience as non-consensual (on the Likert scale), yet a low percentage of women label their experience rape or sexual assault. This disparity implies some women may experience difficulty when attempting to reconcile what is considered a clearly nonconsensual experience with the possibility of labeling oneself as a rape (or sexual assault) victim. Moreover, such difficulties with labeling may indicate that the mechanism through which voicing non-consent impacts the meaning making process may not be through the labeling process. Additionally, the popularity of the miscommunication hypothesis could be a contributing factor to the low levels of labeling. The miscommunication discourse has spread beyond researchers and into intervention programs and the media. Some research suggests that the availability of the miscommunication discourse allows women to explain their experiences in 
a way that allows them to maintain a sense of control (Frith \& Kitzinger, 1997). If, as some studies suggest, maintaining a sense of control is a protective strategy for women who have been raped (Gavey, 1992), one can see how voicing non-consent and having that voice ignored and overruled would contribute to increased distress as found in the current study.

Additionally, prior research attempts to quantify aspects of meaning making after unwanted sexual experiences have often focused on comparing assault characteristics, levels of distress, and aspects of meaning making across types and severity of experiences (i.e., a rape group versus a sexual assault group versus a verbal coercion group) (Littleton \& GrillsTaquechel, 2011). Due to the large sample size of the current study, differences in assault characteristics, symptoms of distress, and aspects pertaining to meaning making were compared among rape victims alone. The ability to compare groups of women with approximately the same severity of experience (i.e., rape), removes potential confounds when examining quantitative differences, and is a strength of the current study.

Finally, it is acknowledged that the tertiary aim of this study, to investigate the impact of voicing non-consent on experiences of sexual assault, was unable to be sufficiently examined due to low sample size. Rather than indicating that only a small number of women experience sexual assault, the low number of women who reported sexual assault $(n=54)$ likely points to a lack of an appropriate measure to ask women about these types of experiences. For example, the version of the MSES used in this study contained only one item unique to sexual assault (e.g., having sex play due to force or threats of force). The revised SES contains a larger number of questions asking about sexual assault, included substance-facilitated sexual assault, however a wide array of acts are lumped together, preventing researchers from knowing which specific act a women is endorsing (Koss et al., 2007). Furthermore, a wide range of sexual assault experiences may not be well represented in quantitative questionnaires. A more through measure of sexual assault is needed, possibly one allowing for qualitative response options. The large number of women who recalled experiences of sexual assault that also met the criteria for rape ( $n=43$ ) is also telling. A full $80 \%$ of women who experienced acts defined as sexual assault (i.e., non-penetrative unwanted sex acts) for sexual assault also experienced rape (i.e., nonconsensual penetration). These findings suggest that, at least within a college sample, acts consistent with sexual assault rarely stop there, and frequently progress to experiences consistent with research 
definitions of rape. This data may prove useful for sexual assault and rape education programs on college campuses.

\section{Limitations}

The findings of the present study contribute to the existing literature and the specific impact voicing non-consent may have. Although this study helps to provide a better understanding of how voiced non-consent may impact women's experience of and responses to rape, it should be acknowledged that this study has several limitations. First, the study sample was homogenous in terms of age (young college aged-women), ethnicity (mostly white), and socioeconomic status (mostly middle and upper class). Therefore, conclusions of this study may not generalize to more ethnically or economically diverse samples of non-college women. Different cultures may hold diverse attitudes about sexuality, unwanted sex, and thus the meaning making process may differ widely in different cultural contexts (Blackwood, 2000; Mackey, 2001). Additionally, as the data provided were retrospective and cross-sectional, temporal assertions or inferences cannot be formed. More information is needed to determine the series of events during an unwanted sexual experience, how unwanted sexual experiences may evolve from consensual sexual acts, and how the timing of voicing of non-consent in this sequence may impact the very meaning behind voicing non-consent and labeling unwanted sexual experiences. For these reasons, future studies should attempt to utilize a more diverse sample, along with a prospective design that would allow for a more complete picture of the process, particularly in illuminating how labeling and meaning changes over time. In addition, future studies would benefit from using mixed methods to obtain both qualitative and quantitative data. Prior research on voicing non-consent has been qualitative (e.g., Gavey 1992, 1995, 1999), while the current study uses quantitative methods. Using both methodologies should allow researchers to get the most complete picture of meaning making and factors that may impact it.

Additionally, although the present study hypothesizes that voicing non-consent is an important factor in the experience of rape, direct measures of meaning making or changes in cognitions were not assessed. Related, although voicing non-consent was hypothesized to increase symptoms of distress as a result of increasing a woman's feelings of helplessness or powerlessness, neither construct was directly assessed. Though women who voiced non-consent did indeed show levels of distress elevated above and beyond those women who did not voice 
non-consent, future studies will need to directly assess helplessness or powerlessness to conclude that these are the mechanisms by which voicing non-consent increases distress.

Lastly it should be noted that methodological factors might have impacted some of the findings of this study. Particularly, it should be acknowledged that due to an administrative error, the RAQ scales were only administered to half of the participants. For this reason, future studies may still entertain examining the impact of voicing non-consent on blame and recovery using a larger sample size. Additionally, having two differing measures to examine the impact of CSA on voicing non-consent may have contributed to a null finding. Studies assessing a more thorough history of CSA may find a relationship between childhood sexual abuse and future voicing of non-consent.

\section{Conclusion \& Implications}

Despite the drawbacks of the present study, the findings provide a more complete descriptive picture regarding the prevalence and correlates of voicing non-consent before or during a rape experience. By examining quantitative issues surrounding the voicing of nonconsent, this study begins to illuminate patterns and legitimize the potential impact of voicing non-consent. The findings also give us a glimpse into how voicing non-consent may directly impact the meaning making process a woman engages in after an unwanted sexual experience. Women who voiced non-consent showed higher levels of PTS symptoms, were more likely to use physical resistance, and showed greater endorsement of the labels of rape, sexual assault, and non-consensual. Findings suggest that women who voice non-consent before or during an experience of rape are likely to view their experience differently than women who do not voice non-consent. Women who voice non-consent are likely to have had different qualitative experiences than women who did not voice their non-consent. Therefore, different factors may need to be addressed as a part of the recovery process for each group of women. For women who voiced non-consent, particular factors to include in a treatment or therapy setting may include themes of feeling helpless or powerless, and how those feelings may contradict efficacious views about the self. Finally, combining the results of the current study with prior research on meaning making suggests that while traditionally structured intervention or psychotherapy programs are likely helpful, it is important to understand that one woman's experience is not equal to another's. It is critical for effective therapists to understand the meaning each woman assigns her 
experience, and how that meaning will contribute to the unique treatment needs of each individual.

If we can generalize from the current study that an overwhelming majority of rape victims expressed clear verbal non-consent and resisted physically, then programs focused on increasing the clarity women use to indicate non-consent (i.e., improve communication) seem unfounded. At best, such programs are likely to lack efficacy, but at worst such programs may be damaging to women by simultaneously promoting victim blame and absolving perpetrator accountability. The findings of the current study, paired with recent findings regarding the inaccuracy of the miscommunication hypothesis (Abbey \& Jacques-Tiura, 2011; Beres et al., 2014), highlight the need for an increased focus on campaigns designed to educate and train individuals about the importance of respecting boundaries and obtaining consent. Campaigns focused on the 'no means no' message are a good place to begin, however, given the role that intoxication appears to play in voicing non-consent, campaigns focused on a 'yes means yes' message are likely to hold even more promise. ${ }^{2}$

\footnotetext{
${ }^{2}$ Some recent campaigns focused on affirmative consent include the enthusiastic consent (e.g., http://www.yesmeansyes.com/consent-0) and consent is sexy campaigns (e.g., http://www.consentissexy.net). These campaigns, which have launched at Tulane University, Loyola University, and West Chester University to name a few, have been met with overwhelming student support. The focus of these programs is on spreading the message that consent is a continuous process rather than a one-time event, that "good" sex and positive sexuality come from making sure your partner is as into the sexual activity as you are, and that ultimately only yes means yes.
} 


\section{References}

Abbey, A., BeShears, R., Clinton-Sherrod, A.M., \& McAuslan P. (2004). Similarities and differences in women's sexual assault experiences based on tactics used by perpetrator. Psychology of Women Quarterly 28, 323-332.

Abbey, A., \& Jacques-Tiura, A. J. (2011). Sexual assault perpetrators' tactics: Associations with their personal characteristics and aspects of the incident. Journal of Interpersonal Violence, 26(14), 2866-2889.

Acierno, R., Resnick, H., Kilpatrick, D. G., Saunders, B., \& Best, C. L. (1999). Risk factors for rape, physical assault, and posttraumatic stress disorder in women: Examination of differential multivariate relationships. Journal of Anxiety Disorders, 13(6), 541-563.

Beck, A. T. (1967). Depression: Clinical, experimental, and theoretical aspects (Vol. 32). University of Pennsylvania Press.

Beres, M. (2010). Sexual miscommunication? Untangling assumptions about sexual communication between casual sex partners. Culture, Health, and Sexuality, 12(1), 1-14. doi:10.1080=13691050903075226

Beres, M. A., Senn, C. Y., \& McCaw, J. (2014). Navigating ambivalence: How heterosexual young adults make sense of desire differences. Journal of Sex Research, 51(7), 765-776.

Berkowitz, A. (1992). College men as perpetrators of acquaintance rape and sexual assault: A review of recent research. Journal of American College Health, 40(4), 175-181.

Berliner, D. (1991). Rethinking the reasonable belief defense to rape. The Yale Law Journal, 100(8), 2687-2706.

Bernstein, D. P., Stein, J. A., Newcomb, M. D., Walker, E., Pogge, D., Ahluvalia, T., ... \& Zule, W. (2003). Development and validation of a brief screening version of the Childhood Trauma Questionnaire. Child Abuse \& Neglect, 27(2), 169-190.

Black, M., Basile, K., Breiding, M., Smith, S., Walters, M., Merrick, M., \& Stevens, M. (2010). National Intimate Partner and Sexual Violence Survey 2010 Summary Report: Executive Summary.

Blackstone, W. (1765). Commentary on the Laws of England. Bk. I.

Blackwood, E. (2000). Culture and women's sexualities. Journal of Social Issues, 56(2), 223238.

Botta, R.A., \& Pingree, S. (1997). Interpersonal communication and rape: Women 
acknowledge their assaults. Journal of Health Communication, 2(3), 197-212.

Briere, J. (1996). Trauma symptom inventory. Odessa, FL: Psychological Assessment Resources.

Brown, A. L., Testa, M., \& Messman-Moore, T. L. (2009). Psychological consequences of sexual victimization resulting from force, incapacitation, or verbal coercion. Violence Against Women, 15(8), 898-919.

Browne, A., \& Finkelhor, D. (1986). Impact of child sexual abuse: A review of the research. Psychological Bulletin, 99(1), 66-77.

Byers, E. S. (1996). How well does the traditional sexual script explain sexual coercion? Review of a program of research. Journal of Psychology and Human Sexuality, 8(1/2), 7-25.

Calhoun, K. S., Atkeson, B. M., \& Resick, P. A. (1982). A longitudinal examination of fear reactions in victims of rape. Journal of Counseling Psychology, 29(6), 655-661.

Centers for Disease Control and Prevention. 2010. National Intimate Partner \& Sexual Violence Survey. Retrieved from cdc.gov/violenceprevention/nisvs/

Chumley, C. (2014, September 29). California Gov. Brown signs 'yes means yes' rape shield law. The Washington Times. Retrieved from http://www.washingtontimes.com /news/2014/sep/29/california-gov-brown-signs-yes-means-yes-rape-shie/

Clay-Warner, J. (2002). Avoiding rape: The effects of protective actions and situational factors on rape outcome. Violence and Victims, 17(6), 691-705.

Cook, S. L., \& Koss, M. P. (2005). More data have accumulated supporting date and acquaintance rape as significant problems for women. Current Controversies on Family Violence, 2, 97-116.

Decker, J. F., \& Baroni, P. G. (2012). No still means yes: The failure of the non-consent reform movement in american rape and sexual assault law. Journal of Criminal Law \& Criminology, 101(4), 1081-1169.

DiLillo, D., Fortier, M. A., Hayes, S. A., Trask, E., Perry, A. R., Messman-Moore, T., ... \& Nash, C. (2006). Retrospective assessment of childhood sexual and physical abuse: A comparison of scaled and behaviorally specific approaches. Assessment, 13(3), 297-312.

Ellis, E. M., Atkeson, B. M., \& Calhoun, K. S. (1981). An assessment of long-term reaction to rape. Journal of Abnormal Psychology, 90(3), 263-266.

Fahrenthold, D. A. (2006, June 19). Statistics show drop in U.S. rape cases. Washington Post. Retrieved from http://www.washingtonpost.com/wp-dyn/content/article/2006/06/18/ 
Finkelhor, D., \& Browne, A. (1985). The traumatic impact of child sexual abuse: A conceptualization. American Journal of Orthopsychiatry, 55(4), 530-541.

Fisher, B. S., Cullen, F. T., \& Turner, M. G. (2000). The Sexual Victimization of College Women. Series: Research Report. NCJ.

Federal Bureau of Investigation. (1991). Crime in the United States: Uniform crime reports. Washington, DC: U.S. Department of Justice.

Frank, E., Turner, S. M., Stewart, B. D., Jacob, M., \& West, D. (1981). Past psychiatric symptoms and the response to sexual assault. Comprehensive Psychiatry, 22(5), 479-487.

Frazier, P. A. (2003). Perceived control and distress following sexual assault: A longitudinal test of a new model. Journal of Personality and Social Psychology, 84(6), 1257-1269.

Frazier, P. A., \& Seales, L. M. (1997). Acquaintance rape is real rape. In M. D. Schwartz (Ed.), Researching sexual violence against women: Methodological and personal perspectives (pp. 54-64). Thousand Oaks, CA: Sage.

Frith, H., \& Kitzinger, C. (1997). Talk about sexual miscommunication. Women's Studies International Forum, 20(4), 517-528.

Foa, E. B., Rothbaum, B. O., Riggs, D. S., \& Murdock, T. B. (1991). Treatment of posttraumatic stress disorder in rape victims: A comparison between cognitive-behavioral procedures and counseling. Journal of Consulting and Clinical Psychology, 59(5), 715-723.

Gavey, N. (1990). Rape and sexual coercion within heterosexual relationships: An intersection of psychological, feminist, and postmodern inquiries (Doctoral dissertation, ResearchSpace@Auckland).

Gavey, N. (1991). Sexual victimization prevalence among New Zealand university students. Journal of Consulting and Clinical Psychology, 59(3), 464-466.

Gavey, N. (1992). Technologies and effects of heterosexual coercion. Feminism \& Psychology, 2(3), 325-351.

Gavey, N. (1999). I wasn't raped, but.. New versions of victims: Feminists struggle with the concept, 57-81. New York: New York University Press.

Gavey, N. (2005). Just sex?: The cultural scaffolding of rape. Routledge.

Gidycz, C. A., \& Koss, M. P. (1991). Predictors of long-term sexual assault trauma among a national sample of victimized college women. Violence and Victims, 6, 175-190.

Gray, E. (2014, May). The sexual assault crisis on American campuses. Time Magazine, 183(20). 
Retrieved from time.com/magazine/us.

Gray, J. (1992). Men are from Mars, women are from Venus: A practical guide for improving communication and getting what you want in your relationships. New York, NY: HarperCollins.

Goldman, R. (2010, April 16). Second accusation emerges against Ben Roethlisberger. $A B C$ News. Retrieved from http://abcnews.go.com/GMA/TheLaw/ben-roethlisbergeraccusation-emerges/story?id=10394816

Harned, M.S. (2004) Does it matter what you call it? The relationship between labeling unwanted sexual experiences and distress. Journal of Consulting and Clinical Psychology, 72(6), 1090-1099. doi: 10.1037/0022-006X.72.6.1090

Harned, M. S. (2013). Treatment of Posttraumatic Stress Disorder and Comorbid Borderline Personality Disorder. In Handbook of Treating Variants and Complications in Anxiety Disorders (pp. 203-221). Springer New York.

Heaney, K. (2012). "She Got What She Wanted”: Blaming the Victim in Newspaper Coverage of Minnesota College Sexual Assaults (2000-2012).

Henneberger, M., \& Shin, A. (2013, August 31). Military's handling of sex assault cases on trial at naval academy rape hearing. The Washington Post. Retrieved from http://www.washingtonpost.com/local/militarys-handling-of-sex-assault-cases-is-on-trialat-naval-academy-rape-hearing/2013/08/31/

Hollon, S. D., \& Garber, J. (1988). Cognitive therapy. In L. Y. Abramson (Ed.), Social cognition and clinical psychology: A synthesis (pp. 204-253). New York: Guilford Press.

Horowitz, M. J. (1997). Stress response syndromes: PTSD, grief, and adjustment disorders. Northvale, NJ: Jason Aronson.

Humphreys, T., \& Herold, E. (2007). Sexual consent in heterosexual relationships: Development of a new measure. Sex Roles, 57(3-4), 305-315.

Janoff-Bulman, R. (1985). The aftermath of victimization: Rebuilding shattered assumptions. Trauma and Its Wake: The Study and Treatment of Post-Traumatic Stress Disorder, Brunner/Mazel, New York, pp.15-35.

Johnson, J. D., \& Jackson, L. A. (1988). Assessing the effects of factors that might underlie the differential perception of acquaintance and stranger rape. Sex Roles, 19, 37-45.

Kahn, A. S., Jackson, J., Kully, C., Badger, K., \& Halvorsen, J. (2003). Calling it rape: 
Differences in experiences of women who do or do not label their sexual assault as rape. Psychology of Women Quarterly, 27(3), 233-242.

Kahn, A. S., \& Mathie, V. A. (2000). Understanding the unacknowledged rape victim. Psychology of Women Quarterly, 4, 377-403.

Kahn, A. S., Mathie, V. A., \& Torgler, C. (1994). Rape scripts and rape acknowledgment. Psychology of Women Quarterly, 18(1), 53-66.

Kanin, E. J. (1967). An examination of sexual aggression as a response to sexual frustration. Journal of Marriage and the Family, 428-433.

Kanin, E. J. (1969). Selected dyadic aspects of male sex aggression. Journal of Sex Research, 5(1), 12-28.

Kilpatrick, D. G. (2004). Making sense of rape in America: Where do the numbers come from and what do they mean? Charleston: National Crime Victims Research and Treatment Center, Medical University of South Carolina. Available from http://www.vawnet.org/ SexualViolence/PublicPolicy/MakingSenseofRape.pdf.

Kilpatrick, D. G., Acierno, R., Resnick, H. S., Saunders, B. E., \& Best, C. L. (1997). A 2-year longitudinal analysis of the relationships between violent assault and substance use in women. Journal of Consulting and Clinical Psychology, 65, 834-847.

Kilpatrick, D. G., Resnick, H. S., Ruggiero, K. J., Conoscenti, L. M., \& McCauley J. (2007). Drug-facilitated, incapacitated, and forcible rape: A national study.

Charleston, SC: Medical University of South Carolina, National Crime Victims Research $\&$ Treatment Center.

Koss, M. P. (1985). The hidden rape victim: Personality, attitudinal, and situational characteristics. Psychology of Women Quarterly, 9, 193-212.

Koss, M. P. (1992). Defending date rape. Journal of Interpersonal Violence, 7, 122-126.

Koss, M. P. (1998). Hidden rape: Sexual aggression and victimization in a national sample of students in higher education. In M. E. Odem \& J. Clay-Warner (Eds.), Confronting Rape and Sexual Assault (pp. 51-69). Wilmington, DE: Scholarly Resources.

Koss, M. P., Abbey, A., Campbell, R., Cook, S., Norris, J., Testa, M., ... \& White, J. (2007). Revising the SES: A collaborative process to improve assessment of sexual aggression and victimization. Psychology of Women Quarterly, 31(4), 357-370.

Koss, M. P., \& Cook, S. L. (1998). Facing the facts: Date and acquaintance rape are significant 
problems for women. In R. K. Bergen (Ed.), Issues in Intimate Violence (pp. 147-156). Thousand Oaks, CA: Sage.

Koss, M. P., Gidycz, C. A., \& Wisniewski, N. (1987). The scope of rape: Incidence and prevalence of sexual aggression and victimization in a national sample of higher education students. Journal of Consulting and Clinical Psychology, 55, 162-170.

Koss, M. P., \& Harvey, M. R. (1991). The rape victim: Clinical and community interventions. Newbury Park, CA: Sage Publications, Inc.

Krause, E. D., DeRosa, R. R., \& Roth, S. (2002). Gender, trauma themes, and PTSD: Narratives of male and female survivors. In Kimmerling, R., Ouimette, P., \& Wolfe, J. Gender and PTSD. New York: Guilford.

Krebs, C. P., Lindquist, C. H., Warner, T. D., Fisher, B. S., \& Martin, S. L. (2009). College women's experiences with physically forced, alcohol-or other drug-enabled, and drugfacilitated sexual assault before and since entering college. Journal of American College Health, 57(6), 639-649.

Layman, M. J., Gidycz, C. A., \& Lynn, S. J. (1996). Unacknowledged versus acknowledged rape victims: Situational factors and posttraumatic stress. Journal of Abnormal Psychology, 105(1), 124-131.

Lebowitz, L., \& Roth, S. (1994). "I felt like a slut": The cultural context and women's response to being raped. Journal of Traumatic Stress, 7(3), 363-390.

Leinwand, D. (2009, October 6). Reported rapes hit 20-year low. USA Today. Retrieved from http://www.usatoday.com/news/nation/2009-10-06-rape-decline_N.htm

Littleton, H. (2007). An evaluation of the coping patterns of rape victims integration with a schema-based information-processing model. Violence Against Women, 13(8), 789-801.

Littleton, H. L., \& Grills-Taquechel, A. (2011). Evaluation of an information-processing model following sexual assault. Psychological Trauma: Theory, Research, Practice, and Policy, 3(4), 421-429.

Lonsway, K. A. (2008). Measuring sexual violence: Methods, misconceptions, and a new (revised) measure. Sexual Assault Report, 12(1), 1-2, 8-13.

Lonsway, K. A. (2010). Trying to move the elephant in the living room: Responding to the challenge of false rape reports. Violence Against Women, 16(12), 1356-1371.

Lonsway, K. A., \& Archambault, J. (2012). The "justice gap" for sexual assault cases: Future 
directions for research and reform. Violence Against Women, 18(2), 145-168.

Lyon, M. (2004). No means no?: Withdrawal of consent during intercourse and the continuing evolution of the definition of rape. Journal of Criminal Law and Criminology, 95(1), 277-314.

Mackay, J. (2001). Global sex: Sexuality and sexual practices around the world. Sexual and Relationship Therapy, 16(1), 71-82.

MacKinnon, C. A. (2001). Logic of experience: Reflections on the development of sexual harassment law. The Geo. LJ, 90, 813-833.

Marshall, L. (2008, January 30). Rape in the U.S. military. Los Angeles Times. Retrieved from http://www.latimes.com/opinion/la-oew-marshall30jan30-story.

McCahill, T. W., Meyer, L. C., \& Fischman, A. M. (1979). The aftermath of rape. Lexington, MA: Lexington Books.

McCann, I. L., \& Pearlman, L. A. (1990). Vicarious traumatization: A framework for understanding the psychological effects of working with victims. Journal of Traumatic Stress, 3(1), 131-149.

McCann, I. L., Sakheim, D. K., \& Abrahamson, D. J. (1988). Trauma and victimization: A model of psychological adaptation. The Counseling Psychologist, 16(4), 531-594.

Messman-Moore, T. L., \& Brown, A. L. (2004). Child maltreatment and perceived family environment as risk factors for adult rape: Is child sexual abuse the most salient experience? Child Abuse \& Neglect, 28(10), 1019-1034.

Messman-Moore, T. L., Coates, A. A., Gaffey, K. J., \& Johnson, C. F. (2008).

Sexuality, substance use, and susceptibility to victimization risk for rape and sexual coercion in a prospective study of college women. Journal of Interpersonal Violence, 23(12), 1730-1746.

Messman, T. L., \& Long, P. J. (1996). Child sexual abuse and its relationship to revictimization in adult women: A review. Clinical Psychology Review, 16(5), 397-420.

Messman-Moore, T. L., \& Long, P. J. (2003). The role of childhood sexual abuse sequelae in the sexual revictimization of women: An empirical review and theoretical reformulation. Clinical Psychology Review, 23(4), 537-571.

Messman-Moore, T. L., Walsh, K., \& DiLillo, D. (2010). Emotion dysregulation and risky sexual behavior in revictimization. Child Abuse \& Neglect, 34, 967-976. 
Mills, C. S., \& Granoff, B. J. (1992). Date and acquaintance rape among a sample of college students. Social Work, 37(6), 504-509.

Motley, M. T. (2008). Unwanted escalation of sexual intimacy: Pursuing a miscommunication explanation. In M. T. Motley (Ed.), Studies in applied interpersonal communication (pp. 121-143). Thousand Oaks, CA: Sage.

Muehlenhard, C. L. (2011). Examining stereotypes about token resistance to sex. Psychology of Women Quarterly, 35(4), 676-683.

Muehlenhard, C. L., \& Felts, A. S. (1986). An analysis of factors related to men's attitudes about the justifiability of date rape. Unpublished raw data.

Muehlenhard, C. L., \& Hollabaugh, L. C. (1988). Do women sometimes say no when they mean yes? The prevalence and correlates of women's token resistance to sex. Journal of Personality and Social Psychology, 54(5), 872-879.

Muehlenhard, C. L., \& Linton, M. A. (1987). Date rape and sexual aggression in dating situations: Incidence and risk factors. Journal of Counseling Psychology, 34(2), 186-196.

Muehlenhard, C. L., Sympson, S. C., Phelps, J. L., \& Highby, B. J. (1994). Are rape statistics exaggerated? A response to criticism of contemporary rape research. The Journal of Sex Research, 31, 144-146.

Norris, J., \& Feldman-Summers, S. (1981). Factors related to the psychological impacts of rape on the victim. Journal of Abnormal Psychology, 90(6), 562-567.

Osman, S. L. (2003). Predicting men's rape perceptions based on the belief that "no" really means “yes”. Journal of Applied Social Psychology, 33(4), 683-692.

Parker, A. D., \& Brown, J. (2000). Detection of deception: Statement validity analysis as a means of determining truthfulness or falsity of rape allegations. Legal and Criminological Psychology, 5, 237-259.

Peterson, Z. D., \& Muehlenhard, C. L. (2007). Conceptualizing the "wantedness" of women's consensual and nonconsensual sexual experiences: Implications for how women label their experiences with rape. Journal of Sex Research, 44(1), 72-88.

Phillips, K. M. (2000). Written on the body: Reading rape from the twelfth to fifteenth centuries. Medieval Women and the Law, 125-144.

Pineau, L. (1989). Date rape: A feminist analysis. Law and Philosophy, 8(2), 217-243.

Power, K. (2012). Luckily he backed off: A mixed methods analysis of undergraduate 
women's consent, attitudes and behaviors. Columbia Social Work Review, 3(1), 46-62.

Rabin, R. (2011, December 14). Nearly 1 in 5 women in U.S. survey say they have been sexually assaulted. New York Times Magazine. Retrieved from www.nytimes.com/2011/12/15.

Rapaport, K., \& Burkhart, B. R. (1984). Personality and attitudinal characteristics of sexually coercive college males. Journal of Abnormal Psychology, 93(2), 216-221.

Remick, L. A. (1993). Read her lips: An argument for a verbal consent standard in rape. University of Pennsylvania Law Review, 141(3), 1103-1151.

Resick, P.A. (1993). The psychological impact of rape. Journal of Interpersonal Violence 8(2), 223-257.

Resick, P. A., Churchill, M., \& Falsetti, S. A. (1990). Assessment of cognitions in trauma victims: A pilot study. In 6th annual meeting of the Society for Traumatic Stress Studies. New Orleans, LA.

Resick, P. A., \& Schnicke, M. K. (1990). Treating symptoms in adult victims of sexual assault. Journal of Interpersonal Violence, 5(4), 488-506.

Resick, P. A., \& Schnicke, M. K. (1992). Cognitive processing therapy for sexual assault victims. Journal of Consulting and Clinical Psychology, 60(5), 748-756.

Resick, P. A., Williams, L. F., Suvak, M. K., Monson, C. M., \& Gradus, J. L. (2011). Long-term outcomes of cognitive-behavioral treatments for posttraumatic stress disorder among female rape survivors. Journal of Consulting and Clinical Psychology, 80(2), 201-210.

Resnick, H.S., Kilpatirck, D.G., Dansky, B.S., Saunders, B.E., Best, C.L. (1993). Prevalence of civilian trauma and posttraumatic stress disorder in a representative national sample of women. Journal of Consulting and Clinical Psychology, 61(6), 984-991. doi: 10.1037/0022-006X.61.6.984

Rosenberg, M., \& Evans, T. (2014, June 30). The case against Darren Sharper. Sports Illustrated. Retrieved from http://www.si.com/nfl/2014/06/25/darren-sharper.

Roth, S., \& Lebowitz, L. (1988). The experience of sexual trauma. Journal of Traumatic Stress, 1(1), 79-107.

Roth, S., Lebowitz, L., \& DeRosa, R. R. (1997). Thematic assessment of posttraumatic stress reactions. In J. P.Wilson \& T M. Keane (Eds.), Assessing psychological trauma and PTSD (pp. 512-528). New York: Guilford Press.

Roth, S., \& Newman, E. (1993). The process of coping with incest for adult survivors 
measurement and implications for treatment and research. Journal of Interpersonal Violence, 8(3), 363-377.

Rothbaum, B. O., Foa, E. B., Riggs, D. S., Murdock, T., \& Walsh, W. (1992). A prospective examination of post-traumatic stress disorder in rape victims. Journal of Traumatic Stress, 5(3), 455-475.

Rubenfeld, J. (2014, November, 15). Mishandling rape. New York Times Magazine. Retrieved from www.nytimes.com/2014/11/16.

Ruch, L. O., \& Chandler, S. M. (1983). Sexual assault trauma during the acute phase: An exploratory model and multivariate analysis. Journal of Health and Social Behavior, 174185.

Russell, D. E. (1982). The prevalence and incidence of forcible rape and attempted rape of females. Victimology: An International Journal, 7, 81-93.

Russell, D. E. (1984). Sexual exploitation: Rape, child sexual abuse, and workplace harassment (pp. 29-66). Beverly Hills, CA: Sage Publications.

Schewe, P. A. (2002). Guidelines for developing rape prevention and risk reduction interventions. In P. A. Schewe (Ed.), Preventing violence in relationships: Interventions across the life span (pp. 107-136). Washington, DC: American Psychological Association.

Testa, M., Livingston, J. A., Vanzile-Tamsen, C., \& Frone, M. R. (2003). The role of women's substance use in vulnerability to forcible and incapacitated rape. Journal of Studies on Alcohol and Drugs, 64(6), 756-764.

Thompson, M. (2000). Life after rape: A chance to speak? Sexual and Relationship Therapy, 15(4), 325-343.

Tjaden, P. G., \& Thoennes, N. (2000). Extent, nature, and consequences of intimate partner violence (p. 62). Washington, DC: US Department of Justice, Office of Justice Programs, National Institute of Justice.

Walker, J. T. (2007). Eliminate residency restrictions for sex offenders. Criminology \& Public Policy, 6(4), 863-870.

Weis, K., \& Borges, S. S. (1973). Victimology and rape: The case of the legitimate victim. Issues in Criminology, 8, 71-115.

Wachen, J. S., Jimenez, S., Smith, K., \& Resick, P. A. (2014). Long-term functional outcomes of 
women receiving cognitive processing therapy and prolonged exposure. Psychological Trauma: Theory, Research, Practice, and Policy, 6(S1), S58-S65.

Weitz, A. J. (2002). Communicative and perceptual factors contributing to date rape: Interviews with perpetrators. Unpublished doctoral dissertation, Illinois University, Carbondale, IL. 
Table 1: Comparison of women who voiced non-consent and those who did not on study variables

\begin{tabular}{|c|c|c|c|c|c|}
\hline & $\begin{array}{l}\text { Voiced } \\
\text { Non- } \\
\text { consent }\end{array}$ & $\begin{array}{c}\text { No Voiced } \\
\text { Non- } \\
\text { consent }\end{array}$ & & & \\
\hline & $\begin{array}{c}\text { Mean } \\
\text { (SD) }\end{array}$ & $\begin{array}{c}\text { Mean } \\
\text { (SD) }\end{array}$ & $d f$ & $F$ & $\begin{array}{c}\text { Partial eta- } \\
\text { squared }\end{array}$ \\
\hline \multirow[t]{2}{*}{ Rape Label } & 2.81 & 1.70 & $(1,196)$ & $10.45^{* * *}$ & .047 \\
\hline & $(1.83)$ & $(1.09)$ & & & \\
\hline \multirow[t]{2}{*}{ Sexual Assault Label } & 3.80 & 1.90 & $(1,197)$ & $25.78 * * *$ & .111 \\
\hline & $(1.97)$ & $(1.35)$ & & & \\
\hline \multirow[t]{3}{*}{ Consensual Label } & 2.44 & 3.43 & $(1,194)$ & $10.77 * * *$ & .055 \\
\hline & $(1.47)$ & $(1.53)$ & & & \\
\hline & $\begin{array}{c}\text { Marginal } \\
\text { Mean } \\
\text { (SE) }\end{array}$ & $\begin{array}{c}\text { Marginal } \\
\text { Mean } \\
\text { (SE) }\end{array}$ & $d f$ & $\boldsymbol{F}$ & $\begin{array}{c}\text { Partial eta- } \\
\text { squared }\end{array}$ \\
\hline Intrusive & 8.56 & 5.17 & $(1,215)$ & $8.15^{* *}$ & .037 \\
\hline Experiences & $(.45)$ & $(1.11)$ & & & \\
\hline \multirow[t]{2}{*}{ Defensive Avoidance } & 10.75 & 7.47 & $(1,215)$ & $8.57 * *$ & .038 \\
\hline & $(.42)$ & $(1.04)$ & & & \\
\hline \multirow[t]{2}{*}{ Dissociation } & 8.59 & 6.45 & $(1,215)$ & $4.17^{*}$ & .019 \\
\hline & $(.39)$ & $(.97)$ & & & \\
\hline \multirow[t]{2}{*}{ Anxious Arousal } & 9.87 & 8.81 & $(1,215)$ & 1.4 & .006 \\
\hline & $(.33)$ & $(.83)$ & & & \\
\hline
\end{tabular}


Table 2: Descriptive Statistics for Variables of Interest

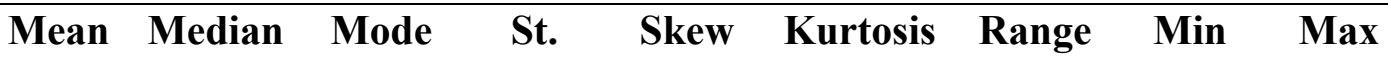 Dev.}

$(n=223)$

Labeling

$\begin{array}{rrrrrrrrrr}\text { Rape } & 2.67 & 2.0 & 1.0 & 1.80 & .98 & -.11 & 6.0 & 1.0 & 7.0 \\ \text { Sex assault } & 3.53 & 3.0 & 2.0 & 2.02 & .38 & -1.14 & 6.0 & 1.0 & 7.0 \\ \text { Non- } & 2.57 & 2.0 & 1.0 & 1.51 & .86 & -.003 & 6.0 & 1.0 & 7.0 \\ \text { consensual } & & & & & & & & & \end{array}$

PTS

symptoms

\begin{tabular}{rccccccccc} 
IE & 8.02 & 7.0 & 1.0 & 6.23 & .72 & -.37 & 24.0 & 0.0 & 24.0 \\
DA & 10.20 & 10.0 & 9.0 & 5.82 & .12 & -.72 & 24.0 & 0.0 & 24.0 \\
DIS & 8.16 & 8.0 & 8.0 & 5.41 & .88 & 1.02 & 27.0 & 0.0 & 27.0 \\
AA & 9.63 & 9.0 & 9.0 & 5.00 & .20 & -.33 & 22.0 & 0.0 & 22.0 \\
\hline$(\mathrm{n}=103)$ & & & & &
\end{tabular}

\section{Recovery}

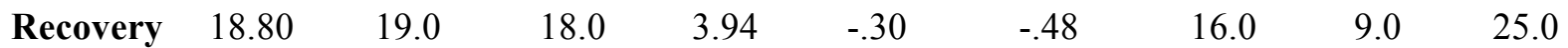

\section{Blame}

$\begin{array}{rccccccccc}\text { Self-blame } & 18.38 & 19.0 & 25.0 & 5.05 & -.48 & -.38 & 20.0 & 5.0 & 25.0 \\ \text { Perp-blame } & 9.92 & 9.0 & 5.0 & 4.50 & .85 & .43 & 20.0 & 5.0 & 25.0\end{array}$


Table 3: Extent Raped Women Label Their Experience Rape

\begin{tabular}{|c|c|c|c|c|c|c|}
\hline & \multirow{2}{*}{\multicolumn{2}{|c|}{$\begin{array}{c}\text { Rape Label } \\
\%\end{array}$}} & \multicolumn{2}{|c|}{$\begin{array}{c}\text { Sexual Assault } \\
\text { Label }\end{array}$} & \multicolumn{2}{|c|}{ Consensual Label } \\
\hline & & & $\mathrm{N}$ & $\%$ & $\mathrm{~N}$ & $\%$ \\
\hline 1.0 (not at all) & 70 & $31.4 \%$ & 37 & $16.6 \%$ & 58 & $26.0 \%$ \\
\hline 2.0 & 46 & $20.6 \%$ & 43 & $19.3 \%$ & 56 & $25.1 \%$ \\
\hline 3.0 & 29 & $13.0 \%$ & 28 & $12.6 \%$ & 29 & $13.0 \%$ \\
\hline 4.0 & 17 & $7.6 \%$ & 27 & $12.1 \%$ & 27 & $12.1 \%$ \\
\hline 5.0 & 15 & $6.7 \%$ & 20 & $9.0 \%$ & 16 & $7.2 \%$ \\
\hline 6.0 & 11 & $4.9 \%$ & 20 & $9.0 \%$ & 6 & $2.7 \%$ \\
\hline 7.0 (completely) & 10 & $4.5 \%$ & 24 & $10.8 \%$ & 3 & $1.3 \%$ \\
\hline Missing & 25 & $11.2 \%$ & 24 & $10.8 \%$ & 28 & $12.6 \%$ \\
\hline
\end{tabular}


Figure 1: Participant Inclusion Breakdown

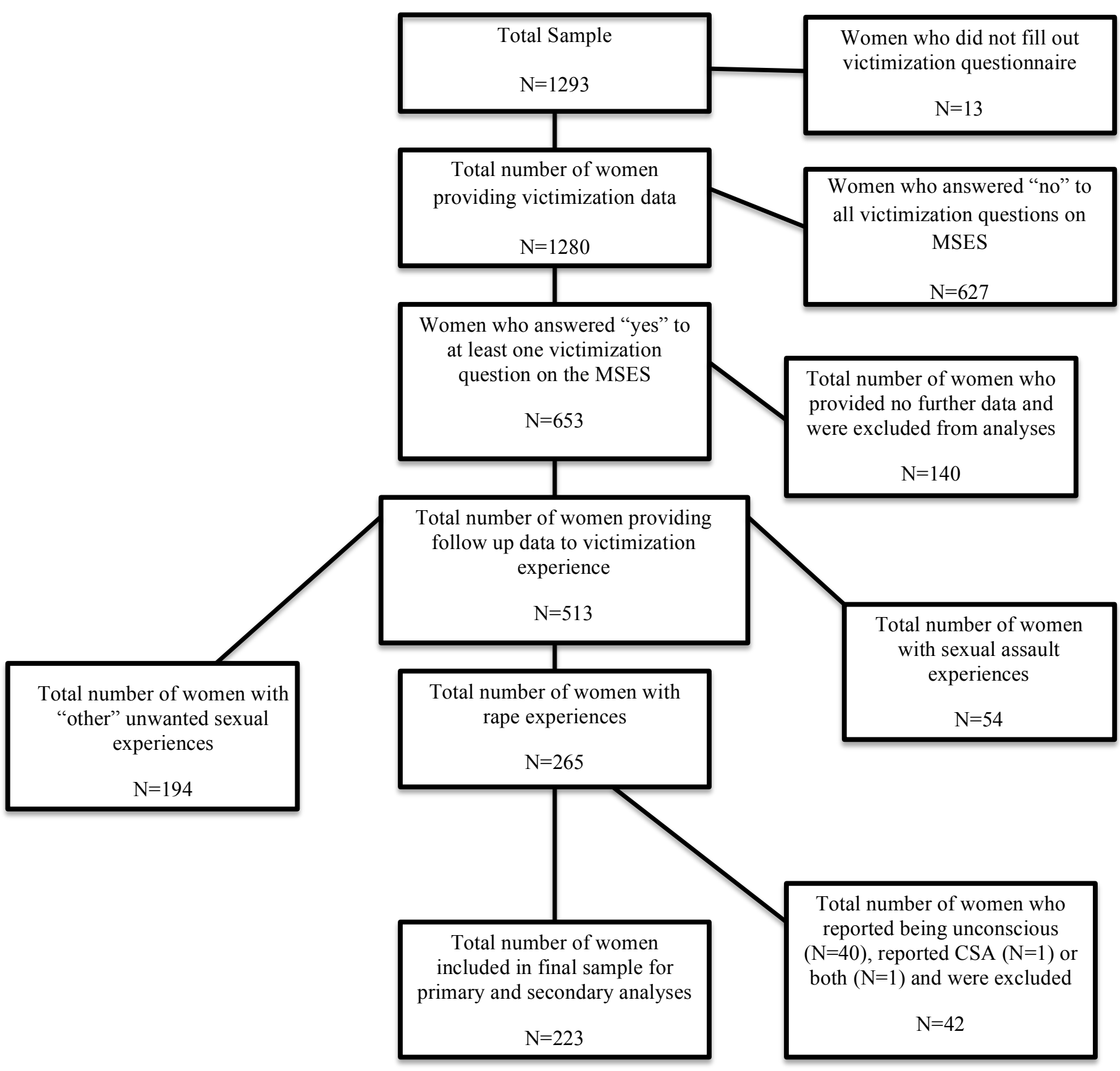

